\title{
Experimental Study of the Pipeline Lubrication for Heavy Oil Transport
}

\author{
A. Bensakhria', Y. Peysson ${ }^{2}$ and G. Antonini ${ }^{1}$ \\ 1 Université de technologie de Compiègne, Centre de recherches de Royallieu, \\ UMR 6067 du CNRS, BP 20529, 60205 Compiègne Cedex - France \\ 2 Institut français du pétrole, 1 et 4, avenue de Bois-Préau, 92852 Rueil-Malmaison Cedex - France \\ e-mail: ammar.bensakhria@utc.fr - yannick.peysson@ifp.fr - gerard.antonini@utc.fr
}

Résumé - Étude expérimentale du transport de bruts lourds par lubrification pariétale - Le transport de matières épaisses joue un rôle important dans de nombreux secteurs économiques, notamment dans l'industrie pétrolière. En effet, les huiles lourdes présentent un grand intérêt pour le renouvellement des réserves d'hydrocarbures car l'ordre de grandeur des quantités en place serait proche des volumes connus d'huiles conventionnelles. Cependant, la très grande viscosité de ces produits complique largement leur exploitation et leur transport.

Dans cette étude, nous proposons l'utilisation d'une technique de lubrification pariétale permettant une réduction importante de la perte de charge d'écoulement lors du transport des huiles lourdes. Cette technique est basée sur l'injection d'un fluide à faible viscosité susceptible de former une couche pariétale entre la paroi de la conduite et l'huile visqueuse formant le noyau de l'écoulement. La déformation du fluide se fait alors préférentiellement dans la couche pariétale de faible viscosité, engendrant ainsi une réduction de la perte de charge globale lors du transport. L'injection de lubrifiant ne se justifie que lorsque la viscosité du produit à pomper est largement supérieure à celle du produit injecté. On obtient alors un profil de vitesse de type «bouchon» dans le pipeline.

Les résultats des essais de lubrification pour une huile lourde ont montré des taux de réduction des pertes de charge dépassant $90 \%$, comparés à ceux obtenus pour la même huile en écoulement non lubrifié. Cette technique permet donc d'envisager des réductions considérables de la puissance de pompage nécessaire pour le transport de pétrole fortement visqueux.

Dans cette étude, nous avons analysé la modification de perte de charge engendrée par la lubrification pariétale ainsi que les différents paramètres de l'écoulement et nous avons mis en évidence le rôle important de la différence de densité entre l'huile et l'eau de lubrification.

\begin{abstract}
Experimental Study of the Pipeline Lubrication for Heavy Oil Transport - Heavy oil is accessible in different areas around the world in large amount. Unfortunately its high viscosity makes it difficult to produce and to transport. In this article we focus on transport problems. Pressure drop in the pipes must be lower as possible to limit pump power and to be able to transport in long distance. In the case of heavy oil, the high viscosity leads to huge pressure drop that makes it impossible to simply pump the fluid in single-phase flow, even of large diameter. Different solutions have been developed to transport heavy oil in pipeline like dilution of the crude oil in a lighter one.
\end{abstract}

In this study we experiment a solution that do not modify the viscosity of the oil phase but transform the flow regime of transport: pipeline lubrication. Pipeline lubrication is a technique based on core-annular 


\begin{abstract}
flow regime and used for pressure drop reduction in the transport of very viscous products. A thin water film adjacent to the internal pipe wall lubricates the internal oil core leading to a longitudinal pressure gradient reduction.

An experimental study has been carried out where the influence of the different parameters, which could affect the lubrication process, has been optimised, using water as the annulus and heavy oil as the core of the flow. The tests were conducted in steady laminar flow at moderate flow rates. The results, obtained with annular water injection at the pipe wall, show a pressure drop reduction over than $90 \%$ as compared with the same product in flow without lubrication. These results confirm the effectiveness of the lubricating process for heavy oil transport. We also showed that density difference is responsible to particular evolution of the pressure drop with the flow rate.
\end{abstract}

\section{INTRODUCTION}

The interest in heavy oil production increased in the recent years because of the large amount of reserve accessible. Estimation of the world reserve is difficult, but the order of magnitude of the total volume of heavy oil is the same that conventional oil. But, a major difficulty with heavy oil is its huge viscosity that makes it challenging to extract. A key issue to assure the production and the transportation of the hydrocarbon phase is to be able to decrease the viscosity. Indeed, mobility is needed in the porous media. The Darcy law shows that for high viscosity, the flow rate is very weak and exploitation is not economical. Enhancement is required for heavy oil production. Hot vapour injection or in situ combustion has been proposed to decrease viscosity in the field by heating. But pipe transportation is also difficult because of the high viscosity.

In this study, we focus on transport properties through pipelines. The simple single-phase flow of heavy oil in a tube will lead to huge pressure drop that makes it impossible to pump. Different solutions are then proposed to allow the flow. Dilution of the heavy oil in a lighter phase is the most common way to reduce friction. Light oil is then needed in very large quantities and recycling is built for industrial development. Light oil is separated at the treatment plant and a second parallel pipe transports it again at the field area. However, the need of light oil is a large limitation of this technique.

In this study, we investigated experimentally a transport solution by Core Annular Flow (CAF). CAF is one particular flow regime where the oil phase is in the centre of the pipe and water is flowing near the wall surface. A very pleasant characteristic of this flow is that the pressure drop is close to that of pure water and does depend only weakly on the heavy oil viscosity!

This remarkable property has been observed for long and its industrial interest was noticed a hundred years ago! A 1904 patent of Isaacs and Speed [1] in the United States mentioned first the ability to transport viscous product through "water lubrication". Despite this early concern, a large-scale industrial pipeline for heavy oil was built only in the 1970's. This Shell line near Bakersflield in California was
$38 \mathrm{~km}$ long for a tube diameter of $15 \mathrm{~cm}$. For more than ten years, a viscous crude oil has been produced at the flow rate of $24000 \mathrm{bbl} / \mathrm{d}$ in water lubricated regime.

Since then, several studies were dedicated to CAF regime, and different reviews of the published work have been written $[2,3]$.

\section{FLOW REGIME}

Several flow regime configurations are possible when flowing a mixture of water and oil in a tube as shown in Figure 1. Multiphase flows of liquid-liquid, gas-liquid are crucial in the oil and gas industry and a large amount of work is available on flow regime characterisation. A complete overview on multiphase flow has been made in the 1970's [4], and two-fluid dynamics are synthesised more recently [5].

The Figure 1 represents various flow regimes when oil and water are flowing for different relative quantity of the two phases. The configurations are depending on the fluid properties such as density, surface tension and also on the shear rate in the flow. Mean injection velocities are also key parameters for the flow regime determination.

For fixed injection flow rate, the Figure 1 represents different configurations obtained when varying the relative amount of oil in water. Emulsion of small droplets is found for few quantity of oil in water. If more oil is added, the droplets are growing in size and became the order of magnitude of the pipe radius. Oil slugs appear in the water phase. With the increase of oil in the system, slugs can merge and the oil phase became continue on the pipe length. Stratified flow and CAF regime are observed in those conditions. When the oil fraction become close to one, we get a continuous oil phase with water droplets.

Core annular flow is one of the flow regimes observed in two-phase flow. But a very specific property is that the pressure drop for the system is the lowest one amount all the other flow regime for the equivalent liquid and water flow rate.

In this flow regime, water is at the pipe surface and lubricates the oil core. Perfect CAF is shown in Figure 2. A small water layer is sheared and the velocity field is 

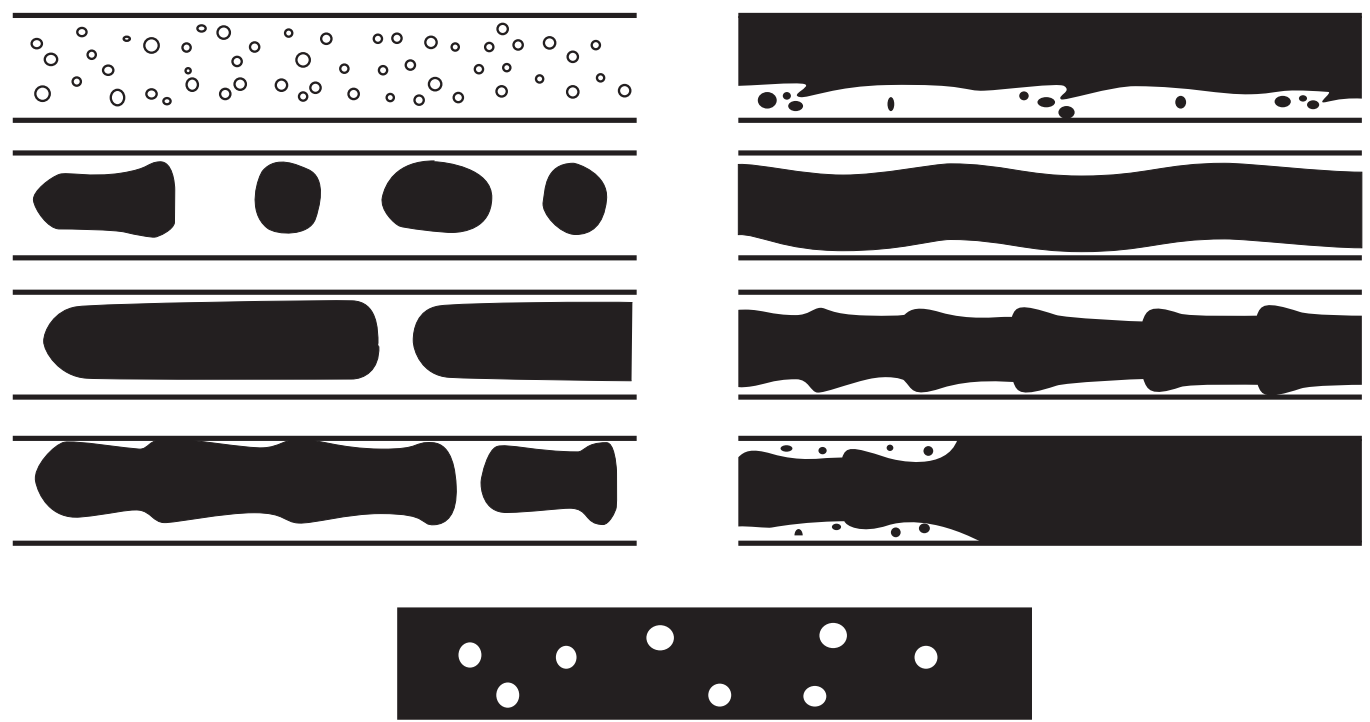

Figure 1

Different flow regimes of two-phase flow (oil in water). From left to right, the relative volume of oil in water is increasing [5].

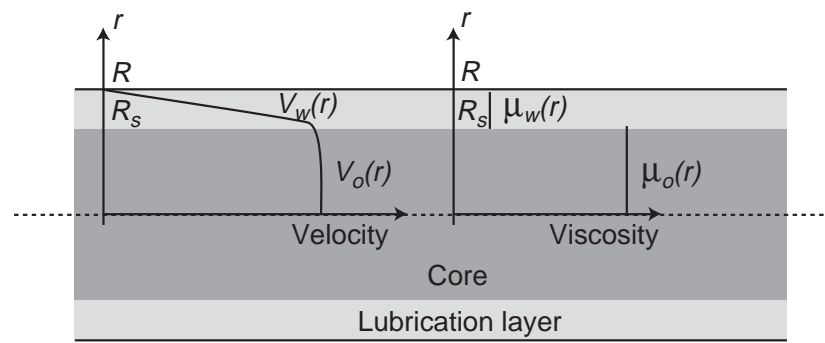

Figure 2

Flow of oil in water in a perfect core annular flow regime. Schematic presentation of the velocity and the viscosity profiles.

approximately linear if the difference of viscosity between oil and water is large. In that case, the oil core is nearly a plug flow. Very weak deformations take place.

Perfect CAF appears to be very rare and can exist only for density matched fluid. Several experimental observation have shown that waves are creating at the water and oil interface [6] leading to Wavy Core Annular Flow (WCAF). This type or CAF seems to be the one observed in real situation. Indeed, for fluids with a difference of density, a buoyancy force will give a radial movement of the core. If no counterbalancing force is applied, the buoyant effect will push the core to the upper wall of the pipe. It has been shown that waves at the interface are necessary to create sufficient lubrication force capable of counterbalancing the buoyancy force [7]. Mechanisms that lead to formation of such wave at the interface are not yet completely understood.

\section{STABILITY}

Many authors investigated the question of the stability of such system. Because of its simplicity, the perfect CAF without density difference was first analysed. It has been shown that stability in this case is achieved for only a small range of parameters [8]. For a fixed volume ratio between oil and water, the core annular flow is not stable at low velocity. The capillary instability due to surface tension appears and breaks the core. But the increase of velocity stabilised the capillary instability and the flow regime can then be observed. But for larger velocity, PCAF flow become again unstable due to the interfacial friction, undulation of the flow arises leading to WCAF. But this configuration can stabilise again. Only much higher velocities can give rise to break up of the core or emulsification process.

The velocity range of existence of CAF is represented in Figure 3 in the case of experimental work reported by [5].

The particular range of stability raised two main problems for industrial development. First, the operating conditions (pump power, pipe geometry, etc.) must be compatible with the stability of the flow, and second, if CAF is not stable at low velocity, the stop and restart of the flow must be addressed specifically.

\section{PRESSURE DROP}

Despite the problems mentioned above, a huge advantage of CAF is that the pressure drop is the smallest one of the twophase flow regime. The transport of very viscous crude oil is then possible with pressure drop of water! Guevara et al. [9] 


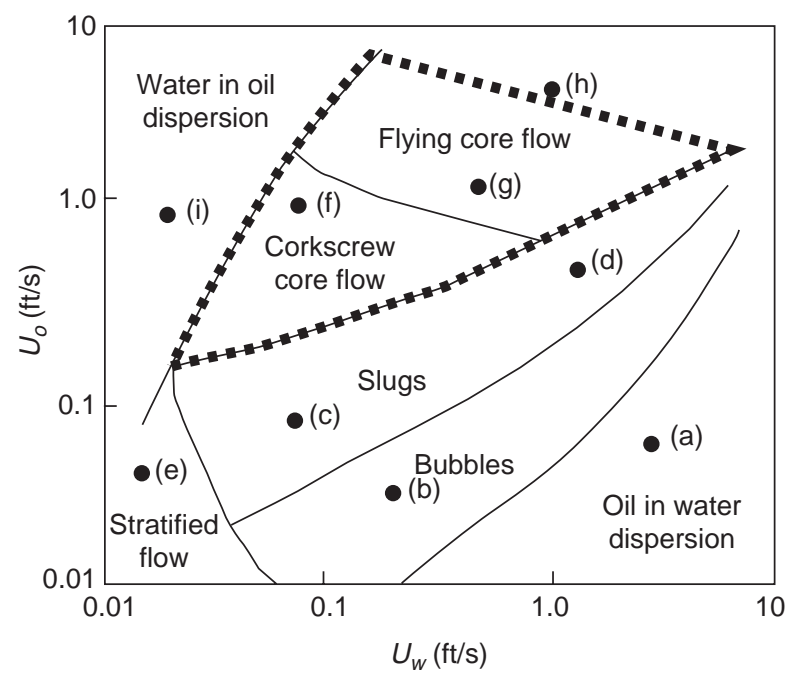

Figure 3

Flow map of oil and water flow. The core annular flow existence is dot line.

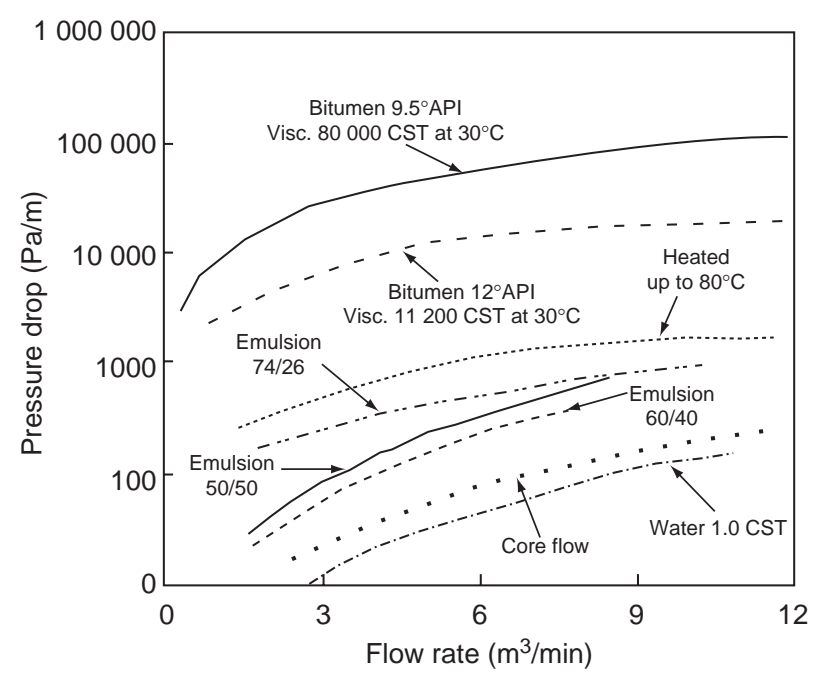

Figure 4

Pressure drop versus flow rate for different transport method for heavy oil. Bitumen only, dilution, heating process are compared. Core flow is one with the lowest pressure drop [9]. compared different processes to transport heavy oil and Figure 4 shows the pressure drop variation with the flow rate for different transportation systems. CAF give rise to the smallest pressure drop not far from pure water in the pipe.

Pressure drop measurement and friction factor estimation have been proposed in the literature. Arney et al. [10] analysed experimentally and theoretically the friction factor variation with a specific Reynolds number in the case of concentric CAF. Eccentricity of the core in the case of density difference has been studied [11] and friction factors were estimated for different position of the core in the pipe.

Very low pressure gradient in the case of CAF raised very much interest from different industry dealing with viscous paste. In the oil industry, the heavy oil transport problem gives rise to large concerns from the operational companies.

\section{INDUSTRIAL DEVELOPMENT}

We already mentioned the Shell line near Bakersfield in California, but a line is also mentioned in the literature to transport the bitumen produced in the area of the Orinoco belt in Venezuela. It was a $55 \mathrm{~km}$ long pipeline transporting highly viscous oil $(1.5 \mathrm{~Pa} \cdot \mathrm{s})$. This commercial line was instrumented to study carefully the capacity of this technique to transport heavy oil in Venezuela [12].

These two lines and some others detailed in different articles [13], showed the capacity of this technique to transport heavy oil at the industrial scale despite the different problems related.
Indeed, restart conditions are not in annular flow regime and restart pressure could be high. A second observation is the adhesion of the oil at the wall in flow conditions. The pipe section can be restricted and increase of pressure drop and even blockage can be observed.

Different solutions have been proposed to overcome these difficulties (cement treatment of the pipe inner surface [14] for example), however, the CAF is not a technique widely used in the oil transport industry certainly because of the unusual behaviour of such system.

In this study, we analysed experimentally the flow of a very viscous heavy oil (around $5 \mathrm{~Pa} \cdot \mathrm{s}$ ) and showed the actual feasibility of CAF to transport heavy hydrocarbon phase.

\section{EXPERIMENTAL SET-UP AND PROCEDURE}

The installation used to perform the experiments consists of a flow loop (Fig. 5) containing the heavy oil storage tank and a stainless steel pipe of $12 \mathrm{~m}$ total length of $25 \mathrm{~mm}$ internal diameter, equips with a fluid lubricant injector, especially designed for pipe-wall lubrication and a data acquisition system.

The heavy oil, stored in a tank of 4501 capacity, is transferred using a screw-type positive displacement (moyno) pump to the center of the injector (Fig. 6) located at the head of the pipe. The flow rate is controlled by the variation of the speed of the pump. Water (fluid of lubrication) is drown from a supply stainless steel tank of 501 and pumped into the annulus of the injector using a volumetric pump, assuring the intern pipe-wall lubrication. 


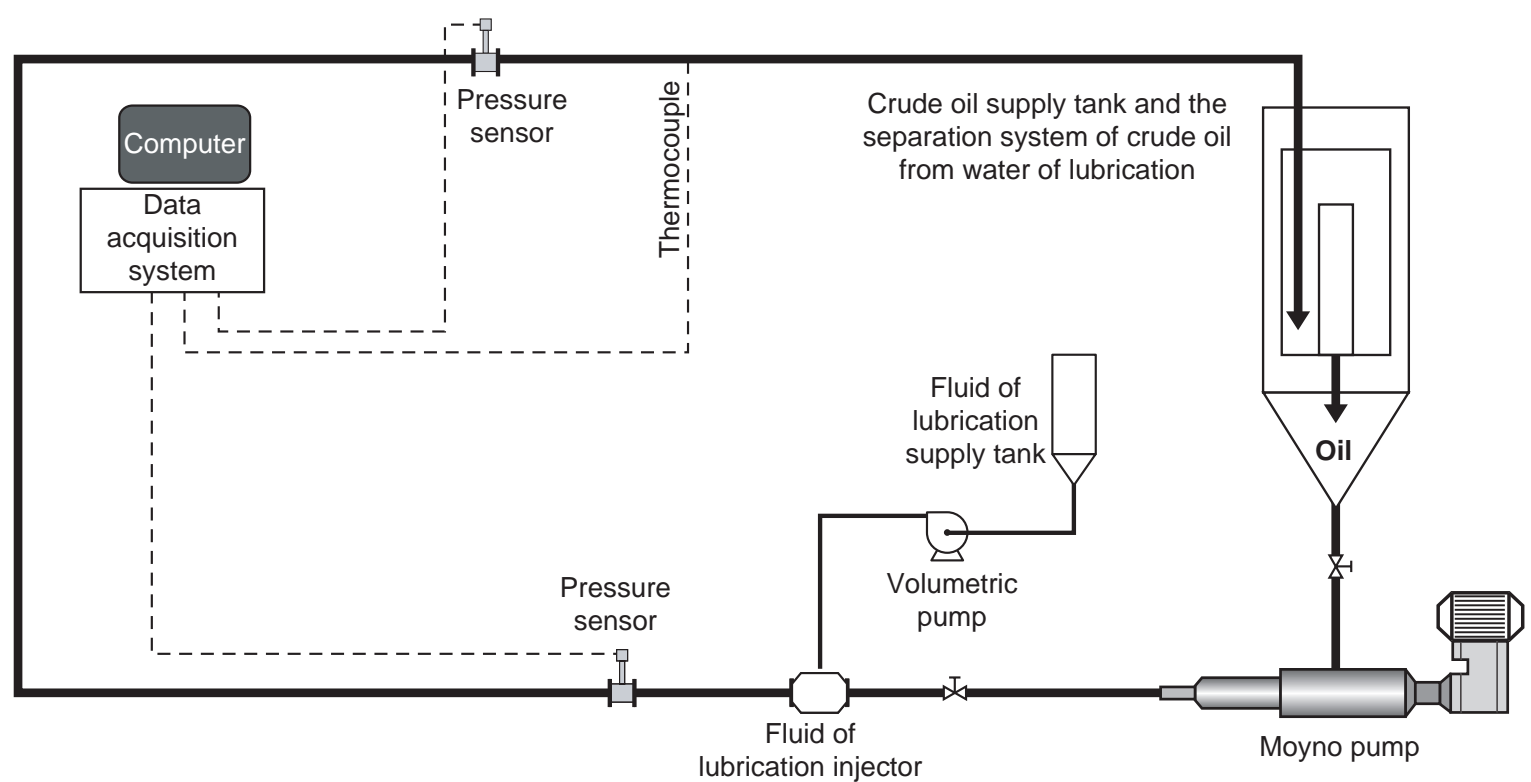

Figure 5

Experimental flow loop diagram.

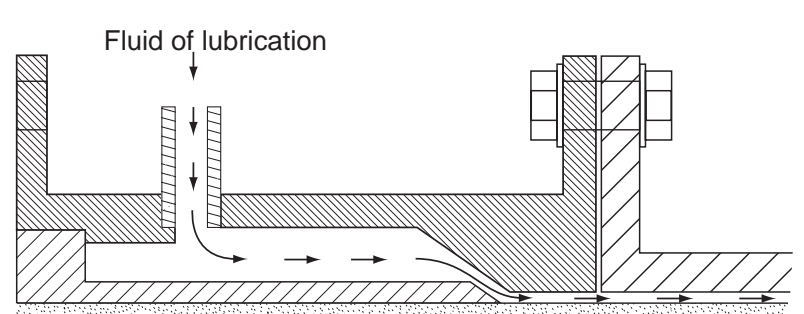

Fluid to be lubricated (core of the flow)

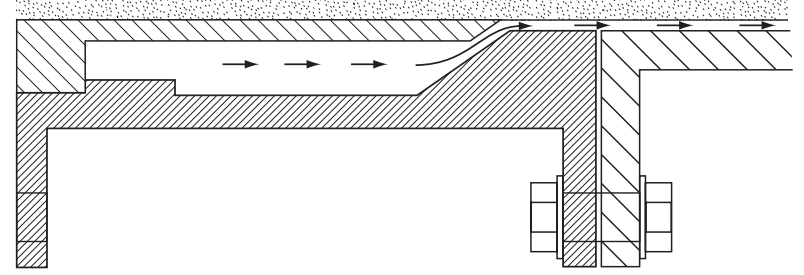

Figure 6

Sketch of lubrication injector.

Pressure drops within the pipeline is measured across a test section of $6 \mathrm{~m}$ long and equipped with two pressure sensors. A recording system coupled to a computer allows the recovery of the pressure sensors signal and the control of the pressure evolution across the test section in real time.

The test procedure consists essentially to follows in real time the variation of the pressure drop of the heavy oil flow with and without lubrication, in order to observe the behaviour and the efficiency of the lubrication process along the conduct.

\section{EXPERIMENTAL RESULTS AND DISCUSSION}

Before the presentation of the pipeline lubrication results, rheological characterisation has been carried out on the oil using the flow loop. The results have been compared with the measurements from a rotary viscometer (Rheometrics RFS II) in order to validate the metrology of the installation used to perform this study.

\subsection{Rheological Study and Validation of the Metrology Used}

Evolution of the pressure drop in the loop with the increase of the flow rate is presented on the Figure 7. A linear evolution is observed which is characteristic of laminar flow regime.

Wall shear stress and shear rate variation can be deduced, according to the following relations:

$$
\begin{aligned}
& \tau=\frac{D}{4} \cdot \frac{\Delta P}{L}: \text { shear stress }(\mathrm{Pa}) \\
& \dot{\gamma}=\left(\frac{32 Q}{\pi D^{3}}\right)=\left(\frac{8 V}{D}\right): \text { shear rate }\left(\mathrm{s}^{-1}\right) ;
\end{aligned}
$$

with:

$\Delta P / L \quad$ linear pressure loss $(\mathrm{Pa} / \mathrm{m})$;

$D \quad$ diameter of the conduct (m);

$Q \quad$ total volumetric flow rate $\left(\mathrm{m}^{3} / \mathrm{s}\right)$;

$V \quad$ flow velocity $(\mathrm{m} / \mathrm{s})$. 


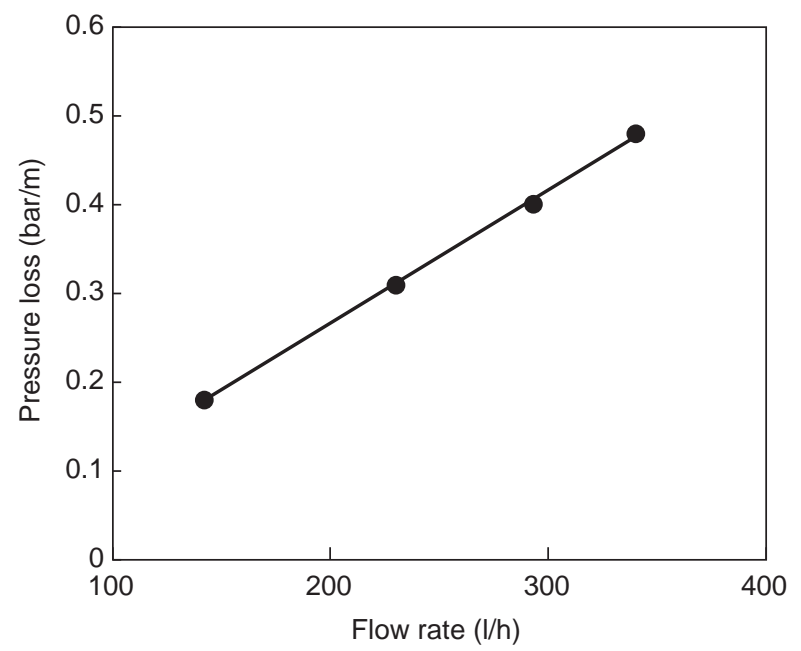

Figure 7

Evolution of the pressure drop versus the volume flow rate.

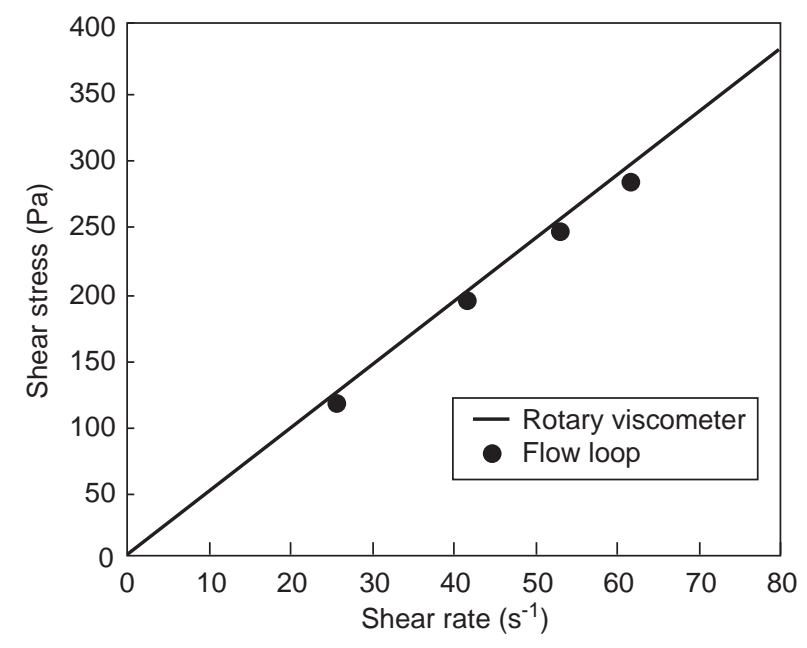

Figure 8

Comparison between the results obtained from the flow loop and those given by the rotary viscometer '"Rheometrics RFS II".
The observed linear evolution of the shear stress versus the shear rate corresponds to a Newtonian behaviour $(\tau=\mu \cdot \dot{\gamma})$ with a viscosity of the heavy oil $\mu=4.74 \mathrm{~Pa} \cdot \mathrm{s}$ at a temperature of $19.7^{\circ} \mathrm{C}$.

In order to validate the metrology of the installation used to perform the lubrication tests, the rheological results obtained from the flow loop, were compared to those obtained from the rotary viscometer 'Rheometrics RFS II'. The result of this comparison is presented on Figure 8, and showed a perfect concordance between the results obtained from the flow loop experiments and those obtained from the rotary viscometer, which validate the metrology of the installation used.

\subsection{Lubrication Process}

\subsubsection{Example of Data Acquisition}

Variation of the pressure drop of the heavy oil with and without lubrication is measured in order to analyse the behaviour and the efficiency of the lubrication process.

An example of data acquisition is given on Figure 9 and shows the influence of the injection of water as lubricant, during the transport of the heavy oil. The applied conditions used for this tests are (Fig. 9a) heavy oil flow rate $=293 \mathrm{l} / \mathrm{h}$ and a flow rates ratio between water and oil of $6 \%$.

The first plateau corresponds to the pressure drop due to the heavy oil flow before injection of the water in the pipe $(0.39 \mathrm{bar} / \mathrm{m}) .250 \mathrm{~s}$ after the beginning of the test, the lubrication fluid is injected. A fall of the pressure loss in the measurement section is observed and pressure drop stabilises around $0.01 \mathrm{bar} / \mathrm{m}$ after $350 \mathrm{~s}$. The flow is then lubricated along of the entire pipe. The superficial velocity for the oil phase in these conditions is $0.16 \mathrm{~m} / \mathrm{s}$. If we consider a linear velocity profile for the water in the lubricated film, the mean velocity is then roughly the half of the oil superficial velocity. The lead to around $140 \mathrm{~s}$ to fill the entire length of the pipe with the water film. This order of magnitude is in very good agreement with the time that it takes to reduce the friction. The injection of the lubrication fluid is stopped at $t=950 \mathrm{~s}$, and with roughly the same time scale, the pressure drop in the pipe increase rapidly to reach its initial value of $0.39 \mathrm{bar} / \mathrm{m}$.

Another example is given in Figure $9 \mathrm{~b}$ where the variation of the pumping pressure versus the time are represented for the following conditions:

- heavy oil flow rate $=340 \mathrm{l} / \mathrm{h}$;

- ratio between the flows rate of water of lubrication and of heavy oil used $=0.06$;

- temperature $=20.1^{\circ} \mathrm{C}$.

\subsubsection{Effect of the Quantity of the Lubrication Fluid and the Flow Rate of Oil}

Lubrication fluid optimisation is achieved by studying the effect of the quantity of the water on the lubrication process efficiency. In these conditions, the parameter is the ratio $\left(Q_{w} / Q_{o}\right)$ between the flow rates of water to oil.

Figure 10 gives the variation of the pressure drop reduction versus water to oil flow rates ratio. These results show that an increase of the pressure drop reduction is observed when we increase the water flow rate. This increase becomes negligible from a value of flow rate ratio of about $6 \%$. Therefore, we can conclude that an optimal lubrication rate associate to a minimal use of the lubrication fluid could be obtained for a flow rate ratio of $6 \%$. 

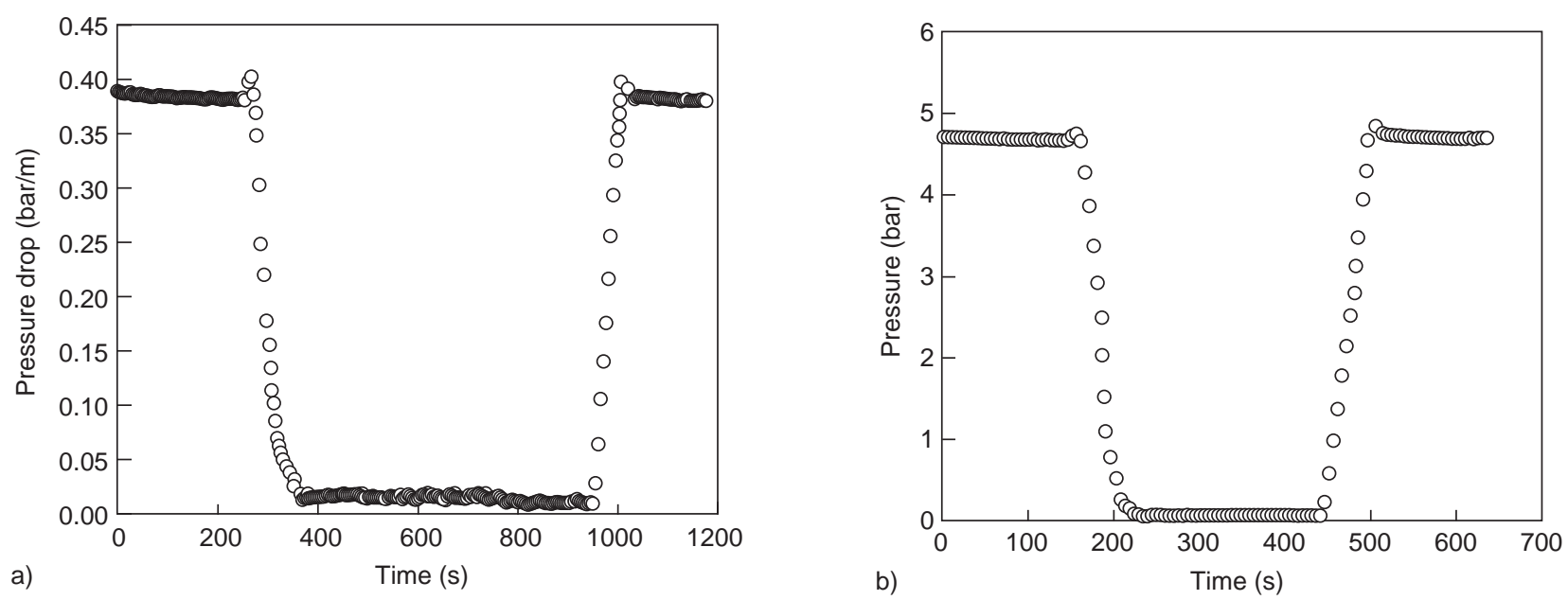

Figure 9

Example of data acquisition of the heavy oil lubrication test.

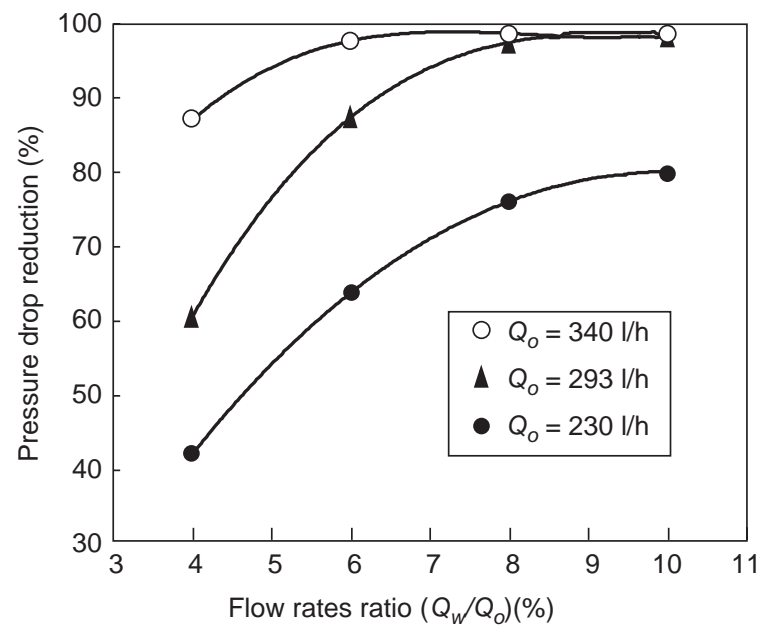

Figure 10

Effect of the ratio between the flow rates of the water and the heavy oil on the efficiency of the lubrication process.

We notice that the pressure drop reduction is calculated according to the following relations:

Pressure drop reduction $(\%)=\frac{\left(\frac{\Delta P}{L}\right)_{1}-\left(\frac{\Delta P}{L}\right)_{2}}{\left(\frac{\Delta P}{L}\right)_{1}} * 100$

with:

$\left(\frac{\Delta P}{L}\right)_{1}:$ pressure drop of the oil without lubrication $(\mathrm{bar} / \mathrm{m})$; $\left(\frac{\Delta P}{L}\right)_{2}$ : pressure drop of the lubricated flow (bar $\left./ \mathrm{m}\right)$.

\subsubsection{Pressure Drop Variation with Flow Rate with and without Lubrication}

The pressure drop in the pipe is measured for different oil flow rate with and without lubrication. Results are presented in Figure 11. Without lubrication, we showed that a linear increase of the pressure drop is observed in very good agreement with the Poiseuille law and an oil viscosity of $4.74 \mathrm{~Pa} \cdot \mathrm{s}$.

For lubricated flow, the flow rates ratio is fixed at $6 \%$ and we increase the oil flow rate (and consequently the water flow rate). Decrease of the pressure drop with flow rate is observed as shown in Figure 11.

This result is remarkable because pressure drop is always increasing with flow rate in usual conditions. The increase rate can be very different for diverse conditions (laminar or turbulent, Newtonian, shear thinning or shear thickening, etc.), but a decrease is rarely observed.

This property is in fact a particular feature of CAF when difference of density between water and oil is present.

\section{Pressure Drops of the Lubricated Flow}

If we assume a "perfect" core annular flow, well centred, as represented in Figure 2, pressure drop can be calculated from the following relation:

$$
\frac{\Delta P}{L}=\frac{Q}{\frac{\pi}{8}\left[\frac{R^{4}}{\mu_{w}}+R_{s}^{4}\left(\frac{1}{\mu_{o}}-\frac{1}{\mu_{w}}\right)\right]}
$$

with:

$\Delta P / L$ pressure drop of the perfect core annular flow $(\mathrm{Pa} / \mathrm{m})$;

$Q \quad$ total flow rate $\left(\mathrm{m}^{3} / \mathrm{s}\right)$;

$R \quad$ pipe radius (m); 


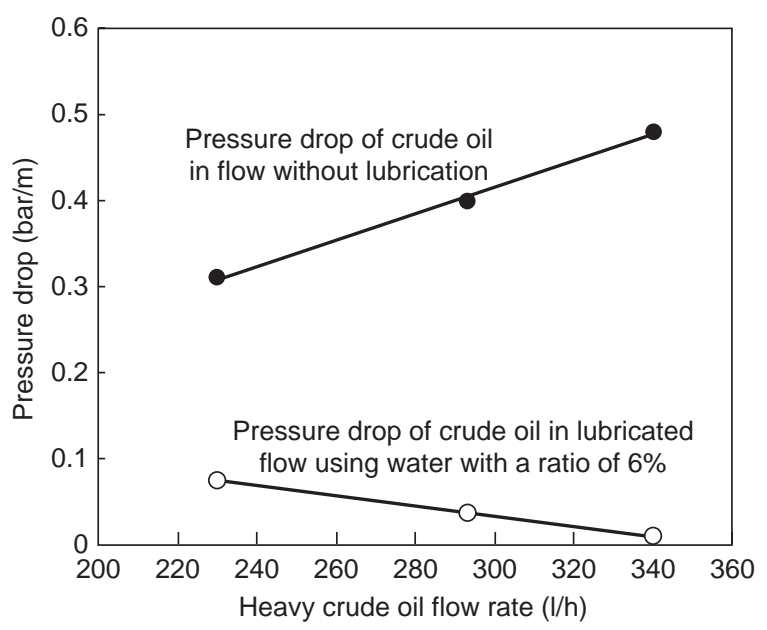

Figure 11

Variation of the pressure drop versus the flow rate of the heavy oil with and without lubrication.

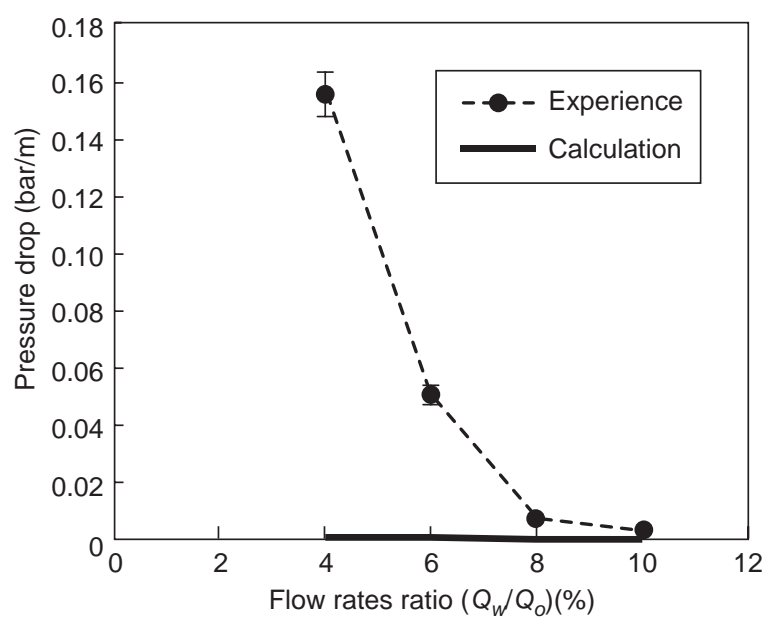

Figure 12

Comparison between experimental and theoretical results giving the variation of pressure drop versus amount of water for CAF flow.
$R_{s} \quad$ core radius $(\mathrm{m})$;

$\mu_{w} \quad$ dynamic viscosity of the water at the pipe wall (annulus) (Pa.s);

$\mu_{o} \quad$ dynamic viscosity of the fluid forming the core of the flow $(\mathrm{Pa} \cdot \mathrm{s})$.

In the case of heavy oil, the viscosity ratio between the two liquids is very high. Indeed, viscosity of oil can be more than 1000 time the viscosity of water! In such condition, we can neglect $1 / \mu_{o}$ in front of $1 / \mu_{w}$.

So pressure drop is only:

$$
\frac{\Delta P}{L}=\mu_{w} \frac{Q}{\frac{\pi}{8}\left[R^{4}-R_{s}^{4}\right]}
$$

$R_{s}$ is simply given by the flow rate ratio $\left(Q_{0}, Q_{w}\right.$ oil and water flow rate):

$$
R_{s}=\frac{R_{0}}{\sqrt{1+2 \frac{Q_{w}}{Q_{o}}}}
$$

As we already mentioned, it's mainly dependent on water viscosity and water layer at the wall.

When lubricated and core centred in the pipe, the pressure drop can be calculated with Equation (2). Maximum flow Reynolds number for water is around 1500, so we assume that the flow is laminar and that Equation (2) can be applied.

Comparisons between calculated pressure drop, and experimental measurements show a large discrepancy as one can see on Figure 12. The pressure drop in the experimental tube is much larger than expected.
As we already pointed out, increase of pressure drop with oil flow rate is attended from Equation (2). But experimentally, the pressure drop is decreasing with oil flow rate if we fixed the ratio of water to oil flow rate to a fixed value (6\% in Figure 11).

These surprising results can be explained if we take into account the density difference between the phases. Indeed, in the case of heavy oil transport, density difference tends to lift the core in the upper part of the pipe (oil density is $800 \mathrm{~kg} / \mathrm{m}^{3}$ ). A schematic of the radial position of the core is given in Figure 13. Lubricating forces tend to push the core in the centre. A competition between the two effects gives a position of the core varying from completely centred, when lubricated force are large (for large velocity) to completely excentred when the core is in the upper part of the pipe touching the wall, when velocity is small. All positions in between are possible.

A simple phenomenological model is proposed to take into account this effect and we will show that in doing so, the experimental observation can be explained.

For liquids flowing in tube, pressure drop is balanced by wall shear stress in steady state conditions. In the case of partially centred annular flow, we divide the pressure drop in two terms: a component due to the water, and a component due to the oil.

In introducing $S$, the mean contact perimeter between the core of the flow (oil) and the wall of the pipe, we approximate the pressure drop as the simple expression:

$$
\frac{\Delta P}{L}=\left(\frac{8}{\pi} \mu_{w} \frac{Q}{R^{4}-R_{S}^{4}}\right)(\xi-1)+\left(\frac{8}{\pi} \mu_{o} \frac{Q}{R^{4}}\right)(\xi) \text { with } \xi=\frac{S}{S_{0}}
$$



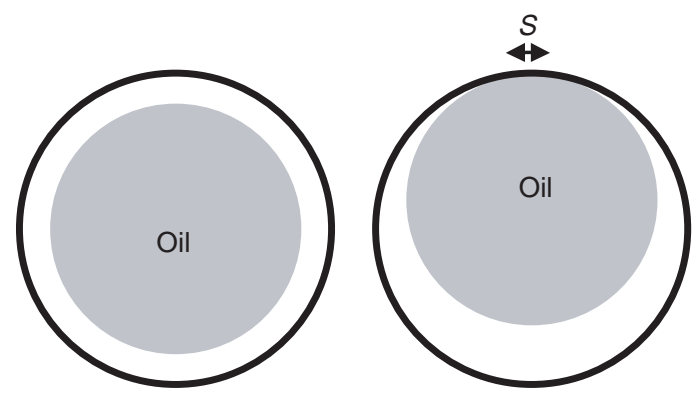

Figure 13

Radial position of the core. (Left, without density difference; right, with density difference. $S$ is the contact perimeter between the oil phase (core) and the wall of the pipe).

$S_{0}=2 \pi \cdot R$ is the perimeter of the pipe, and $S$ is the contact perimeter between the pipe wall and the core of the flow (heavy oil). The model depends only on the ratio $\xi$.

$\xi$ is depending on the density difference, but also on the amount of water injected. For a fixed oil velocity, $\xi$ is decreasing with the amount of water. And for a fixed amout of water, $\xi$ is decreasing with the oil velociy, due to the increase of lubricated effect.

A simple phenomenological function can be choosen to have this behaviour:

$$
\xi=K \cdot e^{-\frac{\varepsilon}{\varepsilon_{0}}} \cdot e^{-\frac{Q}{Q_{0}}}
$$

where $K$ is depending upon density difference, but is fixed in our case.
Qualitative estimation of the pressure drop with Equations (4) and (5) were done. Pressure drop reductions for different oil flow rate and pressure drop with oil flow rate are shown in Figure 14.

The tendencies are in very good agreement with the experimental observation. For a fixed ratio of water to oil flow rate, the pressure drop is decreasing with oil flow rate because the lubricated forces is increasing with velocity and push the core in the centreline. In doing so, water can lubricate all the perimeter of the core and pressure drop is lower. This effect last until the core is well centred in the pipe.

Quantitative calculations were not satisfying with the simple solution proposed in Equation (5) as we can check in Figure 15.

In order to evaluation in more detail the $\xi$ dependency with velocity and amount of water, we try to estimate it from experimental data.

\subsubsection{Perimeter Measurement}

Starting from the experimental measurements, we can calculated the values of $\xi$ that give the presures drop. $S$ is put into Equation (4) to fit the experimental measurements of the pressure drop. In doing so, we get the results reproduced in the Table 1 below.

These results are represented on Figure 16. Evolution of $\xi$ with the two main parameters of our system is shown (amount of water and oil velocity).

From theses results one can observe a decreasing of the ratio $\xi$, with an increasing of the fluid forming the core (oil) flow rate and/or the amount of the fluid lubricant (water). As
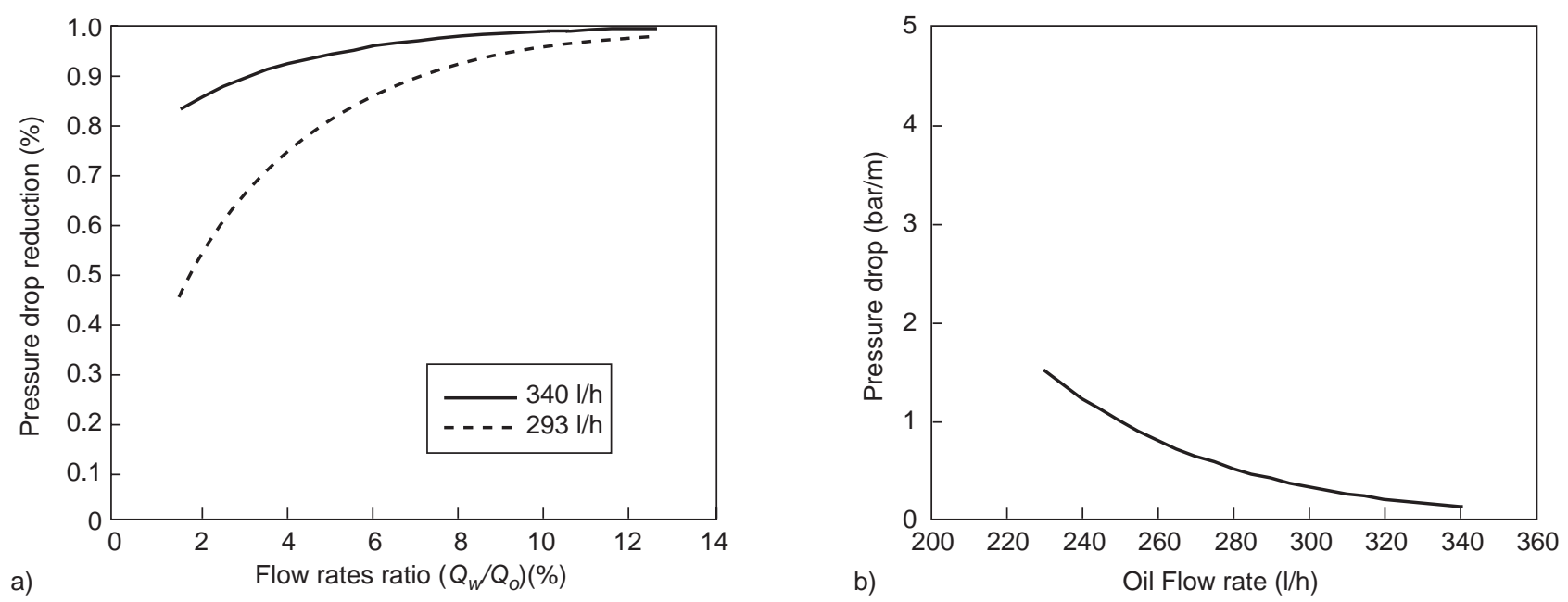

Figure 14

Model calculation of pressure reduction function of amount of water and pressure drop with oil flow rate for a fixed quantity of water. 


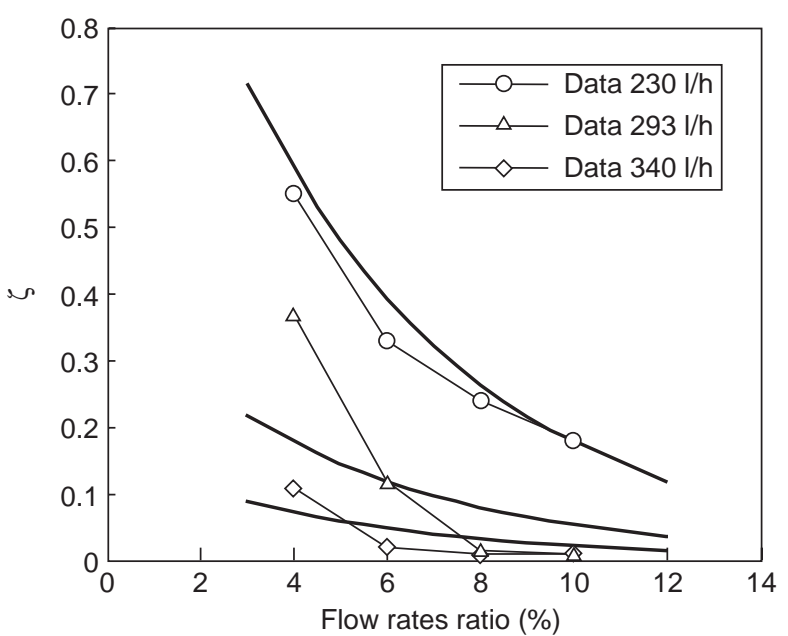

Figure 15

Measurements of $S / S_{0}$ for two oil flow rate and comparison with phenomenological model.

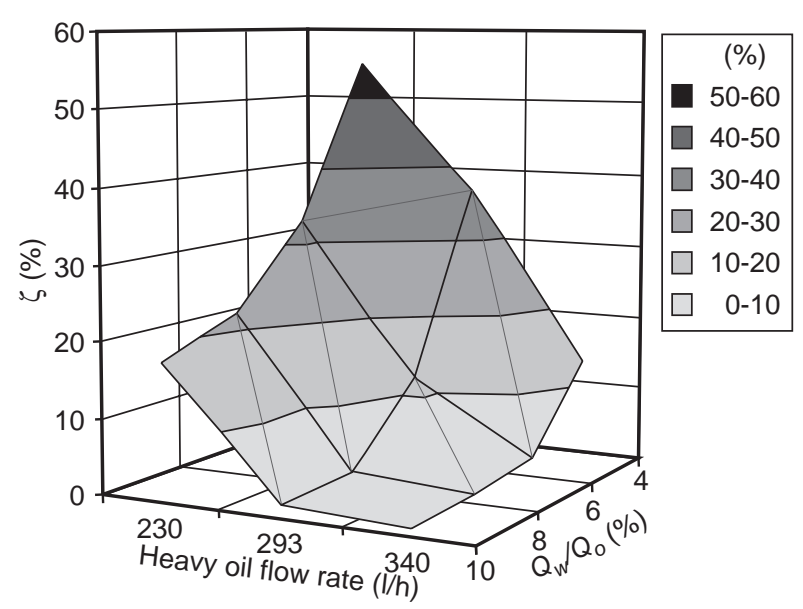

Figure 16

Value of $S / S_{0}$ versus oil flow rate and amount of water from experimental measurements. we discussed before, at large oil velocity, the core is almost centred and $\xi$ is around 0 .

Starting from the parameter envelope calculated and presented in Figure 16, we can determine a correlation function that can reproduce the evolution of $\xi=S / S_{0}$. We can then estimate the pressure drop for heavy oil in large-scale system taking into account the difference of density of the two phases and the fact that the core is not centred in the tube.

TABLE 1

$S / S_{0}$ value calculated to adjust experimental pressure drop results

\begin{tabular}{cccc}
\hline & \multicolumn{3}{c}{ Oil Flow rate } \\
$(1 / \mathrm{h})$ \\
$Q_{w} / Q_{o}$ & $\mathbf{2 3 0}$ & $\mathbf{2 9 3}$ & $\mathbf{3 4 0}$ \\
\hline $\mathbf{0 . 0 4}$ & 0.55 & 0.37 & 0.11 \\
$\mathbf{0 . 0 6}$ & 0.33 & 0.12 & 0.02 \\
$\mathbf{0 . 0 8}$ & 0.24 & 0.015 & 0.01 \\
$\mathbf{0 . 1}$ & 0.18 & 0.01 & 0.01 \\
\hline
\end{tabular}

\section{CONCLUSION}

Heavy oil transportation through pipeline is challenging because of its huge viscosity. In this paper we investigated experimentally a technique based on lubricated flow. The heavy oil is injected at the centre of the pipeline and a small water film is co-injected around it. When water start to be injected, the flow regime converge rapidly to Core Annular Flow and keep stable in time. The flow rate of water is a fixed ratio of the oil flow rate. Pressure measurement shows a reduction of more that $90 \%$ of the pressure drop with lubrication. Variation of the flow rate ratio is done and we observed than for more than $6 \%$ of water flow rate, the pressure reduction reach a plateau depending on the oil flow rate. Reduction is larger for higher flow rate. Variation of the pressure drop with increase of total flow rate is also performed. A very curious observation is made: a decrease of the pressure drop with the increase of flow rate.

To estimate the reduction in pressure drop, the calculation of the pressure drop in the case of perfect core annular flow is done. A large discrepancy is found between calculation and experiment. A simple phenomenological model is then proposed to take into account density difference between oil and water. The buoyancy force tends to lift the core at the top of the tube and the lubrication process tends to centre it. Competition between the two mechanisms lead to an eccentric position of the core and a small part of the oil core is at the wall leading to a contribution of the pressure drop. An empirical estimation of the oil wet perimeter allows the prediction of the decrease of the pressure drop with flow rate and the dependency of the pressure reduction with oil flow rate.

The huge reduction of friction in pipe gives a large industrial interest for this lubricated technique to transport heavy oil. Steady state flow has been demonstrated in this study and the pressure reduction can reach $95 \%$ for some flow parameters. Stop and restart have to be studied to guaranty the complete feasibility for an industrial scale.

\section{REFERENCES}

1 Isaacs, J.D. and Speed, J.B. (1904) Method of Piping Fluids. US Patent $N^{\circ} 759374$.

2 Oliemans, R.V.A and Ooms, G. (1986) Core - Annular Flow of Oil and Water through a Pipeline, in: Multiphase Science 
and Technology. Hewitt G.F., Delhaye, J.M. and Zuber, N., 2, Washington Hemisphere.

3 Joseph, D.D, Chen, K.P. and Renardy, Y.Y. (1997) Core Annular Flows. Ann. Rev. Fluid Mech., 29, 65.

4 Govier, G.W. and Aziz, K. (1972) The Flow of Complex Mixture in Pipes, Von Nostrand Reinhold Company.

5 Joseph, D.D. and Renardy, Y.Y. (1993) Fundamentals of Two-Fluids Dynamics, New York Springer-Verlag.

6 Bai, R., Chen, K. and Joseph, D.D. (1992) Lubricated Pipelining: Stability of Core-Annular Flow. Part 5. Experiments and Comparison with Theory. Journal of Fluid Mech., 240, 97-132.

7 Ooms, G., Segal, A., Van der Wees, A.J., Meerhof, R. and Oliemans, R.V.A. (1984) A Theoretical Model for CoreAnnular Flow of a Very Viscous Oil Core and a Water Annulus through a Horizontal Pipe. Int. Journal of Multiphase Flow, 10, 1, 41.

8 Prezioki, L., Chen K. and Joseph, D.D. (1989) Lubricated Pipelining: Stability of Core-Annular Flow. Journal of Fluid Mech., 201, 323-356.

9 Guevara, E., Gonzales, S.A. and Nunez, G. (1998) Highly Viscous Oil Transportation Methods in the Venezuelan
Oil Industry. Proceedings of the 15th World Petroleum Congress.

10 Arney, M.S., Bai, R., Guevara, E., Joseph, D.D. and Lui, K. (1993) Friction Factor and Holdup Studies for Lubricated Pipelining - Experiments and Correlations. Int. J. Multiphase Flow, 19, 6, 1061-1076.

11 Huang, A., Christodoulou, C. and Joseph, D.D. (1994) Friction Factor and Holdup Studies for Lubricated Pipelining - Laminar and k- $\varepsilon$ Modes of Eccentric Core Flow. Int. J. Multiphase Flow, 20, 3, 481-491.

12 Guevara, E., Zubillaga, V., Zagustin, K. and Zamora, G. (1991) Core Annular Flow: Preliminary Operational Experience and Measurements in a $152 \mathrm{~mm} * 55 \mathrm{~km}$ Pipeline. Proc. 5th Unitar Heavy Crude and Tar Sands International Conference, 5, Caracas, Venezuela.

13 Joseph, D.D., Bai, R., Mata, C., Sury, K. and Grant, C. (1999) Self-Lubricated Transport of Bitumen Froth. Journal of Fluid Mech., 386, 127.

14 Arney, M.S., Ribeiro, G.S., Guevara, E., Bai, R. and Joseph, D.D. (1996) Cement-Lined for Water Lubricated Transport of Heavy Oil. Int. Journal of Multiphase Flow, 22, 2, 207.

Final manuscript received in September 2004 or distributed for profit or commercial advantage and that copies bear this notice and the full citation on the first page. Copyrights for components of this work owned by others than IFP must be honored. Abstracting with credit is permitted. To copy otherwise, to republish, to post on servers, or to redistribute to lists, requires prior specific permission and/or a fee. Request permission from Documentation, Institut français du pétrole, fax. +33147527078 , or revueogst@ifp.fr. 